\title{
Study on Education Research Force of University Teachers
}

\author{
Shiqin Liao \\ Jiangxi Institute of Fashion Technology, Nanchang, 330201, Jiangxi, China \\ 353613980@qq.com
}

Keywords: Research force; Education; University teachers; Theory; Science

\begin{abstract}
Education research force is the advanced ability of teachers who learn to ask questions, thinking and research the education problems. The teaching practice and education research needs teachers to improve education research. Education research, having scientific research similar characteristics, is a kind of study of science based on the fact. Education research needs theoretical guidance which has an impact on education research. The basic process of education research includes asking questions, collecting data, test hypotheses, come the conclusion of the process. In order to improve education research force, some strategies in practice could be followed.
\end{abstract}

\section{Introduction}

At present, the problem of education research force to the teachers has come into notice, but the thesis or research result about it is not enough. Some research said that education research force is the key content of teacher professionalization, which could be carried out among normal university students through project learning [1]. In fact, education research force is not only the requirement of the normal university students, but also the teachers who works in university, which is a necessary ability for the staff that cares about education career. Education research force means that the teachers have the abilities to ask education questions, ponder about education questions and research education questions, which is the advanced ability of teacher's major development. How to cultivate and improve the education research force is discovered in the thesis. In other words, the three tasks could be understood into 3levels: pass the basic knowledge to the students through the teaching is the primary level; pass the update knowledge to the students is the middle level; cultivate the students' research ability and creative spirit is advanced level. In this sense, class teaching is the prepare of education research and is the premise for forward research work. Most important, it would provide an opportunity to foster moral development and ethical decision-making in residents [2].

\section{Why We Need Education Research Force?}

Firstly, the teaching practice requires the teachers to have certain education research ability. Generally speaking, the teaching is the basic task of the teachers. The teaching contains 3 aspects: pass the basic knowledge of the subjects to the students; pass the latest and update knowledge of the subjects to the students; cultivate the students' ability to ponder over the problems and research the problems.

Secondly, the teachers' research environments require the teachers to have certain education ability. Professor Feng Changgen who is the vice president of China Association for Science and Technology had said that having or not having the research results are the criterion to evaluate her of his success or not in the academy community. This means that the teachers need write the scholar papers which are accepted by the peer review and published in the Journal or Periodical [3]. When it comes to write or publish the papers, many people all complain about the difficulty. On one hand, doing the education research needs much time like other research, but the task of teaching is too heavy; on the other hand, even some teachers take a lot of time and rack their brains to do the education research, it will wait for a long time to be published or not being published at all due to other factors. However, whether like it or not, it is an important step of going success to announce the research data, found facts, and research conclusions. 
Thirdly, enhancing education research force is the need to speak well China education story. Science research is not only listen story, but also telling story. For many years, our education research model is listening story from other country scholars, and to some extent, we have been accustomed to listening story from other country experts, then copy the story from others. As a teacher, we should have the ability not only listening story, but also the ability of telling story, telling ourselves stories which could be used to guide our teaching practice. There is no doubt that enhancing education research is the primer of telling our story and telling well of our story.

\section{Science Features of Education Research}

Education research belongs to science research. Generally speaking, research has relationship with science. The aim of science is to obtain knowledge. About science research, the US National Research Council pointed out that in the book of Education Science: education science, nature science and social science have different research fields and methods, but the essence of the science research is similar. They thought that science research contains 6 aspects:

One is the problem which is important and could be proved; Two is that the research should have the relationship with the involved theory; three is that the research should have direct research methods; four is that the research should have logical reasoning; five is that the research could be repeated and popularized; six is that research results should be opened, accepting the review and criticizing from the experts [4]. As those aspects mentioned in above, except repeated research of the fifth, others are also the principles of doing education research.

Of course, social research and nature science research have some differences. Generally speaking, the social researchers do not pay much attention to the control environment conditions, random sample and repeat research, they are often the active participants and promote the research process through their effects; predict the future on the base of theory. The social researcher often explained the past things and the research conclusions are not certain, meaning that is possible but not absolute [5].

According to the analysis in above, obtaining the object acquaintance of the study objects through observation is the basic features of education research. The objectivity means the research conclusion could be open and accept the social query, criticism and practice test.

The main aim of education research is promoting object knowledge through putting new opinions, ideas and hypothesis. As you know, the objective knowledge could be proved to be true or false. In order to promote the new and objective knowledge, education research needs pursuit, challenge and surpass the former knowledge. How to promote new knowledge? Some scholar had said that putting the thinking as conceptualization is a good way, and forming the problem which is worth being researched further to fill the knowledge gap.

\section{The Relationship between Education Research and Education Theory}

Mostly in developing countries laboratory equipment for education and research is very expensive [6]. Theories is the general idea or explain which is formed when solving questions, is a set of concept and logical system which used to explain relative problems. The theory is different from the idea. The idea is just the answer to some special problems, but the theory is the answers to many problems.

In science research, it is necessary to master some theory which is used to solve and explain problems. Something that could not be explained by the theory or could not be classified into the theory frame may have no use or be very important. Just through the research and analysis of the problems that the existing theory could not explain, the researchers could draw the new theory and make new explains to the problems.

How to evaluate the reasoning and progress of a theory? Science philosopher Karl Popper gave a criterion: new theory could explain all that existing theory could explain or not explain [7].

Similarly, education theory is the production of education research in a certain time, and is an expression to pursuit the truth. During the process, the new education theory is the inherit or overrunning towards former theory and shows a certain reasoning and progress. 
Education theory is appearing through education research, the education theory could instruct the education research. The value of education theory's guide to education research lies in interpretation of education theory.

The application of established measures of engagement is novel and provides insights into specific teaching methods for enhancing the engagement of particular groups of students at the course level [8]. As for education theory, we could introduce from advanced countries. What is more important, we should create. Just like telling other people's story, even we learned the theory which is put out by other counties well; we could become a good teacher or a professor, but never could become a leading figure in education trends. However, mastering a certain education theory, no matter west or east, is very important.

\section{Basic Process of Education Research}

Education research is a complicate process. How to understand the process? First, we must learn to put forward questions. Any theory is an explanation to some question. When one theory could not explain new problem or have conflict with new things, modification or correction towards the existing theory is necessary, even putting forward a new theory, which not only explain the existing questions, but also new problems. How to put forward new question? Here are two ways: one is vertical, whether the question has been put forward by others in history; what are the opinions on the problem? Had the problem proved to be false? Two is horizontal, whether the problem had been put forward in other countries, what are the opinions? Whether the problem was prove false. Finally, according to our research, put forwards the problem that we need to solve.

Second, collecting information solved the problem. Before researching questions, the researcher could not know the conclusion. The process of correcting information is the process of continual thinking. We must analyze and identify the database to ensure which database had been used by other researchers and which had not been discovered. When correcting information, we should find the relevance and coherence of all opinions in logic.

Third, use information with science. We should avoid choose the information that we like when do research, we must consider all information to ensure the objectivity of the conclusion. We should not meet the needs of the conclusion to change the information randomly, depending on the authority entirely should be abandoned. The opinion from the authority may be a clue of drawing the conclusions for the researchers. However, we must modify or abandon it if the opinion from the authority does not fit the information.

We must put forwards the hypothesis which is used to solve the problem after the researched problem and relevant information are determined. On one hand, put the research problem into several sub-problems according to the research subject and the documentation; on the other hand, put forward the hypothesis relevant to the problem. What is more important, we must draw some conclusions on the base of hypothesis logically. Of course, research conclusion should not have the tendentiousness. Education research is not purely the hobby, the aim of which is to enhance the growth and progress of the knowledge.

\section{Strategies Used to Promote Education Research Force}

Firstly, Strategy of Putting Forward Problems. In education research, we must seize the key problem, putting the problem into several sub-questions which are relevant but different in essence. According to research need, we just research the sub-questions thoroughly in an appropriate way. Hypothesis should be put forward on the base of the problem which need solving and conclusion. In education research, answers or conclusions from others are just the base for our further research. It is real research to put forward new answers based other researchers.

We must notice that the hypothesis may become the research problem if the hypothesis could not solve the problem that we put forward. In this dilemma time, we must analyze the relationship of the hypothesis and problem, why we could not draw conclusions under the hypothesis? Or the hypothesis 
itself is wrong at the beginning. We must ponder over the hypothesis again if the hypothesis is wrong. We must modify the hypothesis or put forward other hypothesis which is suitable to the research problem. There is no doubt that the problem is existing forever, but the hypothesis could be changed and the hypothesis is used to serve the research problem.

Secondly, Strategy of Drawing Conclusion. It is important to draw conclusion in education research. At present, many researches just pay attention to the description of research process, methods and technology means, which also happens in the abstract of research papers. Generally speaking, research conclusion is a whole conclusion. In our research, every part should have a conclusion based on the argument, we get the whole conclusion based on the every part conclusion. The conclusion must be correct and reasonable. In order to draw the conclusion, we could ask questions to ourselves: what is the whole conclusion? Does the evidence is enough? Does the reasoning process is logical?

Thirdly, Strategy of Being Loyal to Facts. Education research is empirical researches which need practice from two aspects: logical thinking practice of researchers and holding to the facts. In education research, logical thinking practice is scare and we have not special curriculum to cultivate logical thinking. Logical thinking mostly depends on the researchers themselves through attentive observation. It is well known that we all have the tendency agreeing our position, hypothesis and idea. If the position, hypothesis and idea were conflict, the researchers would suffer from the puzzle. Under the circumstance, the researchers would modify the problem or fluctuate the research conclusion. However, if the researchers were loyal to the facts, but not their opinions, they could face and analyze the problem frankly. Every problem has reason and could be explained. Facing new problems, some of which we could find reasons, other problems which could not be explained are just the problems that we need research and draw conclusion from.

\section{Summary}

In brief, modern society is a plural society, and modern education is so on. The in-determination of knowledge and ultra-answers of problems determine education research could not a close process, but a process being always open and accepting challenges. The tangled relationship between education research and policy has received little serious scrutiny, even as paeans to "scientifically based research" and "evidence-based practice" have become a staple of education policymaking in recent years [9]. For this reason, education researchers must keep research situation and vigorous energy to make new interpretation and enhance education research force. Future studies on the effect of curriculum change should include an assessment of the impact on student study strategies [10].

\section{References}

[1] L. F. Wang: the Effective Cultivation of Normal University Students' Education Research Force

[2] On the Base of Project Learning [J]. Modern Education Science, 2013.

[3] A R. Chew: Research and Responsibility: Best Practices in Resident Education [J]. Academic Radiology, 2016. Information on http://www. News. Sciencenet. cn

[4] The US National Research Council. Education Science Research [M]. Translation: Zheng Yan, Beijing: Education Science Publishing House, 2006, pp3-4, pp76-77.

[5] P. P. Kopacek, M. Shala, K. Ismaili, F. Sylaj: Research and Education with Scrap [J], IFAC Proceedings Volumes, 2013, Vol.46 (8)

[6] F. Q. Guo: Reality, Dependency and Universality: Three Levels of Education Theory [N]. China

[7] Social Paper. 2013-08-14.

[8] Peter Balan, Mike Metcalfe: Identifying Teaching Methods that Engage Entrepreneurship Students [J]. Education + Training, 2012, Vol.54 (5), pp. 368-384. 
[9] F. M. Hess: When Education Research Matters [L], Society, 2008, Vol.45 (6), pp.534-539.

[10]Cooles Philip E, Harrigan-Vital Miscilda, Laville Agnes: Student performance and grading changes in a systems-based curriculum[J]. Medical education online, 2014, Vol. 19, pp.23165. 